\title{
On Vague Reference in College English
}

\author{
Jianhe Ma \\ College of Foreign Languages, Tianjin Polytechnic University, Tianjin 300160, China \\ E-mail: majianhe@tjpu.edu.cn
}

\begin{abstract}
We often come across examples of vague reference in English learning, especially college English learning. On entering college, students tend to feel at a loss since their vocabulary is required to be enlarged rapidly and a variety of reference patterns are included in their learning materials which mostly come from American and European original works. Trying to break away from those traditional researches, this paper proposes to generalize the concept of reference from the perspective of pragmatic functions and analyzes a variety of vague reference phenomena.
\end{abstract}

Keywords: Reference, Vagueness, Pragmatic functions, Analyze

\section{Introduction}

With a traditional view, a variety of reference phenomena are manifested by pronouns. Halliday and Hason summarize five types of textual cohesion, including reference, substitution, ellipsis, conjunction and textual cohesion. Among these, reference is mainly achieved by co-reference pronouns and substitution pronouns. For instance, personal pronouns, possessive pronouns and reflexive pronouns are generally used as co-reference pronouns while indefinite pronouns are usually used as substitution pronouns. In semantics, the definition of reference only applies to a certain range. Liejiong Xu (1990) distinguishes situations in which words can refer to others independently from those in which words cannot. In his theory, nouns and some pronouns fall into the first type while others such as verbs, adverbs, prepositions and connections fall into the second. Most non-English majors, lacking in systematic learning of English grammar, have no clear idea about reference phenomena due to complicated reference patterns as well as constantly emerging situations of vague reference. Accordingly, this paper puts forward a generalized reference theory from the perspective of pragmatic functions so as to help college students to smoothly cope with those practical problems brought about by all kinds of vague reference. Here vagueness doesn't mean real vagueness but those reference phenomena hard to clarify due to the distraction of some factors. In the following samples, the bold parts are to be studied in our research.

\section{Theoretical Basis}

Among all the theories on reference, most of them are about grammar. In Zhenbang Zhang's New English Grammar, pronouns are refined and the reference phenomena realized by them are named reference. It is pointed out that a pronoun is accompanied by its antecedent and this tends to be reflected in the context. According to the prepositional relations of pronouns and the referred subjects, pronoun reference can be divided into anaphoric reference and cataphoric reference. In anaphoric reference which points backward, the pronoun refers to the referred subject which comes ahead of it, such as in "Because Ann had never spoken before an audience, she was nervous.". Reversely, in cataphoric, the pronoun is placed ahead of the referred subject, such as in "As he himself is a doctor, my father wants me to choose medicine for a profession.".

Substitution, which refers to a method to avoid lexical repetition, is also mentioned in grammar. There are three substitution phenomena in English: nominal substitution, verbal substitution and clausal substitution, producing three kinds of substitutes, that is, nominal substitutes, verbal substitutes and clausal substitutes. For example:

I prefer the new edition to the old ones. ("ones" refers to "editions".)

The door was falling to pieces. The windows were doing too. (doing=falling to pieces)

"He's leaving for Beijing tonight, you know?" "So I’ve heard." ("so" substitutes for the previous clause)

According to English grammar, personal pronouns, possessive pronouns and reflexive pronouns are co-reference pronouns while indefinite pronouns are substitution ones. Those lying between the two poles can be used as either of them in different situations and therefore hard to distinguish. For example:

"I am going to Majorca for two weeks."

"Where's that?"

Here, "that" referring to the same place as "Majorca", is a co-reference pronoun. However, from another perspective, "that" can be used to avoid the repetition of "Majorca", hence a substitution pronoun as well. 
As is pointed out by Saussure (1980[1949]) in Course in General Linguistics, language as signs (phonic codes) has to be signified; Otherwise, language cannot exist as entities. This theory further points out the close relations between the signified and the signifier. He holds that language can only survive by connecting the signified with the signifier, without either of them no language will come into being at all.

Actually, the vagueness of English words originates from objective reality where all those represented by words have a transitional state. When learning about such objective reality, people tend to endow the referred objects or phenomena with their subjectivity due to unavoidable subjective initiative as well as limitations in their cognition, hence vague reference. Generally speaking, vagueness is an objective attribute of human beings' natural language (Wen).

Functional linguistics represented by Halliday conducts studies on lexical reference from the perspective of functional linguistics. By systematically dividing language into different sections, they explain the relationship between language and the world, language and society and sentences in discourse with the concepts of ideational function, interpersonal function and textual function and reveal the complexity of language application. Overall, they try to describe and explain language features at the semantic level, the grammatical level and the phonetic level with the functions language is expected to exert in social communication (Gong, 2003). Based on a series of analysis on the existing theories of reference, this paper tries employing a generalized reference theory from the pragmatic function perspective to explain all phenomena of vague reference. That is to say, any fact in which a word refers to a thing or a concept can be called reference. Thus anticipatory reference in attributive clauses, numeral reference, adjective reference, adverb reference, substitution, abstract reference to concreteness, concrete reference to abstraction, euphemism reference, metonymy reference, reference following a dash or a comma in addition to traditional reference patterns constitute the whole picture of reference.

\section{An Analysis on a Variety of Vague Reference Phenomena}

In this paper, emphasis will be attached to those vague reference phenomena, including pronoun reference, anticipatory reference in attributive clauses, substitution, abstract reference to concreteness, concrete reference to abstraction, adjective reference, adverb reference, a part referring to a whole as well as some special phenomena with apparent reference.

\subsection{Pronoun Reference}

Since pronoun reference is most universal in English, it won't bring about big problems to English learners. Some particular sentences, however, may challenge readers' understanding due to some distractions. For instance,

(1) I've become one with my machine, taking data in, spitting them out, just another link in the net. In this sentence, "one" doesn't mean "a" or "a person" but "the whole".

(2) On the train ride home, I sat with a jar of strawberry jam on my lap. It reproached me the entire trip.

Here "it" is hard to understand. Actually it represents "a jar of strawberry jam", but this idea may confuse students because they don't think strawberry jam can reproach a person. Obviously, this is an example of personification.

(3) None of us will ever forget our first winter. we were buried under five feet of snow from December through March while one storm after another blasted huge drifts up against the house and barn, we kept warm inside burning our own wood, eating our own apples, and loving every minute of it.

In my teaching, few students can figure out what "it" refers to here, hence revealing their poor ability in understanding long sentences. "It" should refer to "our first winter". Students' failure in understanding it lies in the high span between the two expressions.

(4) It is our way to force ourselves or our organization on people who don't wish us or it.

Many students fail to understand what "it" refers to in this sentence. We find out "us" refers to "ourselves" and "it" refers to "our organization".

\subsection{Anticipatory Reference in Attributive Clauses}

Generally this type of reference is easy to figure out, with the exception that there are several antecedents or coordinate clauses in one sentence. For example,

(5) Yet Dolly, who looked for all the world like hundreds of other lambs that dot the rolling hills of Scotland, was soon to change the world.

Two relative pronouns, "who" and "that", seem to introduce two coordinate attributive clauses. But actually they are not coordinate with "who" referring to "Dolly" while "that" to "other lambs". 
(6) We'll see vehicles and roads that see and hear and feel and smell and talk and act.

Students may be confused by the two antecedents, "vehicles" and "roads", as well as the six successive verbs including "see", "hear", "feel", "smell", "talk" and "act". Here, "that" refers to the whole of "vehicles and roads".

(7) First, I wish for us, of course, the simple common sense to achieve world peace, that being paramount for the very survival of our kind.

Here students may also be confused by the word "that" here. Actually, this is an absolute structure in which "that" is the logic subject referring to "world peace".

\subsection{Substitution}

As is mentioned above, substitution usually covers three types. Although most of them are quite easy, we need to be careful as well.

(8) He carefully picked up his pole. He felt his heart pounding. He was sure the crowd did, too.

In this sentence, the use of "did" is a substitute to avoid the repetition of "feel his heart pounding".

(9) Some days, he feels like surrendering. But his dead mother's challenge echoes in his soul. So, too, do the voices of those who believed him stupid, incapable of living independently.

Here "do" in this sentence substitutes for "echoes in his soul" to avoid repetition.

(10) Porter's hearing is the one perfect thing his body does.

"Does" in this sentence isn't a substitute for any notional verb but means "owns".

\section{4 abstract reference to concreteness and concrete reference to abstraction}

(11) Moreover, one can not stop inquiring minds from thinking about basic science, whether or not they are paid for it.

"Inquiring minds" is an abstract concept referring to "persons who are curious about science".

(12) She explained: "If your feeling for me has any reality, any honest basis, what I looked like won't matter."

"Has any reality" here is a concrete expression referring to an abstract concept---"is real" or "true". (13) Her lips and chin had a gentle firmness, and in her pale green suit she was like springtime come alive.

"Springtime" in this sentence may confuse students. Actually, it is an example of concrete reference to an abstract concept of "young blood".

(14)And I just wanted you to know that I'll do anything I can to help him through life's dangerous sea.

"Life's dangerous sea" is an example of concrete reference to abstract concept, meaning dangers in all aspects in our life.

\subsection{Adjective Reference}

(15) After about two years, I found Tony in our familiar meeting spot. He seemed to stand a little straighter. He was heavier.

"Heavier" is an adjective reference meaning "a bit fatter".

(16) Suppose I am plain (and you must admit that this is more likely).

In this sentence, "plain" is an adjective reference meaning "not pretty; not beautiful or even ugly".

(17) While black conductors were often motivated by their painful experiences; whites were commonly driven by religious convictions.

Here "whites" refers to "the white people".

\subsection{Adverb Reference}

There is seldom reference in adverbs because they have no fundamental influence on people's understanding of semantics. However, the following mentioned adverbs are exceptions which not only are adverbial modifiers modifying the predicate but have specific connotations.

(18) Luxuries are those things that would be nice to have if costless. Necessities are those things we must have regardless.

Here "regardless" refers to "even if they cost quite a lot".

(19) What he says is not genuine, but most people think otherwise. 
Here "otherwise" refers to "in a different way" or "just the opposite".

\subsection{Parts Referring to the Whole}

(20) I am not much of a hand at writing.

Here "a hand" refers to "a person with experience of the stated kind".

(21) I suppose it has something to do with the appeal of an optimistic approach to life----- and the fact that extraordinary deeds have been accomplished by determined individuals who refused to believe "you can't" was the final word on their dreams.

Despite its original meaning, here "word" refers to "judgment".

\section{Some Special Cases of Apparent Reference}

In college English texts, some phrasal verbs with the pronoun "it" are hard to understand. Actually, such a structure is no longer a form with entire reference function but an idiom with special meanings, such as take it (guess, think), blow it (spoil), make it (manage, catch), see to it (ensure), foot it (go on foot), fight it out (compete), funk it (flee from battle) and so on.

(22) But I take it he's someone you've known quite a while?

Here "take it" means "guess or think" as a whole.

(23) A: "But I needn't have hurried, he never turned up."

B: "Did he funk it at the last moment?"

In this sentence, "funk it" means "fail to show up out of fear".

\section{Conclusion}

All issues mentioned in this paper are selected from our teaching practice. From a traditional perspective, these seem to be too generalized and overlap with other fields. From the pragmatic function perspective of reference, however, such a research is off practical importance.

\section{References}

Chen, xianglan. (2005). A General Survey of Researches on Functionalism. Foreign Languages Research. (19): pp5-50.

He, Yingyu. (2005). Semantics. Shanghai: Shanghai Educational Press.

Li, Yinhua. et al. (2005). College English Integrated Course. Shanghai: Shanghai Foreign Language Education Press.

Wang, Zhenjing. (2006). Application of Cohesion in English Writing. Foreign Languages in China. (51): pp43-38.

Yang, Chenghu. (2001). Research on Duplicate Reference and Grammaticalization. Jilin: Jilin People's Press.

Zhang, Zhenbang. (1997). New English Grammar. Shanghai: Shanghai Foreign Language Education Press. 